\title{
Endogenous control of fuelling in a migratory songbird
}

\author{
Ivan Maggini $^{1,2}\left(\right.$ Marc Bulte $^{2} \cdot$ Franz Bairlein $^{2}$
}

Received: 26 March 2017 / Revised: 4 October 2017 / Accepted: 6 October 2017 /Published online: 17 October 2017

(C) The Author(s) 2017. This article is an open access publication

\begin{abstract}
The Northern wheatear (Oenanthe oenanthe) is a small long-distance migratory songbird that breeds throughout the Northern hemisphere and winters in sub-Saharan Africa. The main components of its migratory behaviour, i.e. seasonal migratory restlessness and body mass changes, have been shown to be under endogenous control. However, it is still unknown whether the disposition to accumulate fuel reserves is an inherited trait. We cross-bred Northern wheatears from two populations known to accumulate different amounts of fuel in a common-garden setup, and measured their maximum fuelling as the difference between the lightest and heaviest body mass recorded over each year for 4 years or longer. We used the largest value as a measure of maximum voluntary fuelling potential. F1-generation "hybrids" showed intermediate values to those of the parent populations. It was previously shown that in the wheatear the amount of fuel accumulated is closely linked to the presence of large ecological barriers to cross. This study shows that this adaptation has been fixed at the genetic level, and that intermediate traits are transferred to the next generation, with possible implications on the viability of such individuals in nature.
\end{abstract}

Communicated by: Alexandre Roulin

Electronic supplementary material The online version of this article (https://doi.org/10.1007/s00114-017-1514-0) contains supplementary material, which is available to authorized users.

Ivan Maggini

ivan.maggini@vetmeduni.ac.at

1 Konrad-Lorenz Institute of Ethology, University of Veterinary Medicine, Vienna, Austria

2 Institute of Avian Research "Vogelwarte Helgoland", Wilhelmshaven, Germany
Keywords Innate patterns $\cdot$ Inheritance $\cdot$ Fattening Oenanthe oenanthe

\section{Introduction}

Migratory restlessness, the migration-related nocturnal activity of migratory songbirds in captivity (Gwinner 1968), has been shown to be genetically controlled and inherited (Berthold and Querner 1981). Species or populations of the same species with different migration distances show migratory restlessness which resembles the respective migration behaviour and migration distance in wild conspecifics (e.g. Berthold 1974; Berthold and Querner 1981; Gwinner 1990; Bulte and Bairlein 2013). It has also been shown that the total amount of fat accumulated by migrants prior to migration differs depending on the distance to be covered. In short/ medium-distance migrants, fat accumulation is smaller compared to long-distance migrants which often double body mass prior to migration (Alerstam 1990; Battley et al. 2004; Gill et al. 2009). In contrast to migratory restlessness, however, migratory fat accumulation does not seem to directly reflect overall migration distance but rather the mode of migration and whether a species or population is confronted with an ecological obstacle such as sea or desert (Maggini and Bairlein 2010).

The Northern wheatear (Oenanthe oenanthe), hereafter wheatear, is a migratory songbird with a broad geographic breeding range, spanning large parts of the Holarctic. The $O$. o. leucorhoa subspecies breeds in Iceland, Greenland, and in eastern Canada, and the nominate $O$. o. oenanthe is found in Europe, Asia, and Alaska. The O. o. seebohmi subspecies is found in the Atlas Mountains of Northern Africa. All populations spend the winter in northern sub-Saharan Africa (Keith et al. 1996; Förschler et al. 2008), which means 
that some populations must cover enormous distances, as recently shown for wheatears from Alaska and Canada (Bairlein et al. 2012), whereas others fly much shorter distances. In addition, the birds from Canada, Greenland, and Iceland (O. o. leucorhoa) fly hundreds of kilometres across the northern Atlantic Ocean with no opportunities for resting and refuelling. Consequently, trans-oceanic wheatears have to store large amounts of fuel to be able to cross the barrier successfully (Bairlein and Gwinner 1994; Maggini and Bairlein 2010) while birds migrating over land regularly replenish fuel stores and keep lower fuel loads (Delingat et al. 2006).

The large variability in migratory phenotypes in the wheatear allows us to use this species for testing the genetic basis of fuelling in a common-garden experiment. Previous work showed that the diversity of patterns and extent of migratory behaviour is also revealed by wheatears in captivity (Bairlein et al. 2013). Captive naive wheatears from populations with different migratory routes and facing different ecological barriers showed endogenous population-specific differences in their migratory restlessness and other migratory traits such body mass variation (Maggini and Bairlein 2010) similar to what has been already reported for several other songbird species (Gwinner 1968; Berthold et al. 1972; Gwinner and Biebach 1977; Gwinner 1986; Holberton and Able 1992; Berthold 1996; Cadée et al. 1996; Helm and Gwinner 2006).

Two previous studies investigated the patterns of inheritance of body mass in a common-garden setup (Berthold and Querner 1982; Derégnaucourt et al. 2005). Both studies crossed birds from non-migratory with birds from migratory populations of the same species and found intermediate body mass patterns in the first generation of hybrids. In this study, we used long-term captive wheatears birds from two populations that both express migratory fattening but to a different extent (Maggini and Bairlein 2010) to confirm that fuelling traits are inherited and to test the hypothesis that first generation hybrids inherit intermediate traits. In contrast to previous studies, we did not focus on one single migration season but recorded yearly fuelling maxima by subtracting the minimum (lean) body mass from the maximum body mass reached by a single bird each year over $4+$ years. We then took the largest of the measured maxima as a measure for maximum voluntary fuelling potential. This value shows the highest possible amount of fuel that is voluntarily accumulated by each individual, which we believe could be a measure of the physiological predisposition to accumulate (mostly) fat. In contrast to the previous studies, we did not focus only on the first year of life but on several years of life, in many cases throughout the whole life of an individual. To assess whether maximum fuelling is an inherited trait we cross-bred wheatears of two different populations with known differences in seasonal body mass patterns (Norway and Iceland; Maggini and Bairlein 2010). Migratory restlessness as well as other migratory traits has shown intermediate phenotypes during cross-breeding experiments (Berthold and Querner 1981; Helbig et al. 1994), so we predicted that the cross-bred offspring (hereafter F1hybrids) would show intermediate maximum voluntary fuelling potentials with respect to those of their parent populations.

\section{Methods}

We measured yearly minimum and maximum body mass, and the difference between the minimum and maximum body mass in birds from two populations of wheatears (Norway and Iceland) which were taken from their nests before fledging and then kept in a common-garden setup for their entire life. We measured the same variables in birds from crossbroods between the two populations and in pure Norwegian offspring. The maximum difference between minimum and maximum yearly body mass was used as a measure of maximum voluntary fuelling potential. For details on the methods see the Electronic Supplementary Materials.

\section{Results and discussion}

There was a moderate year-to-year repeatability in the measurement of minimum body mass (63\% [CI95, 50-75\%]), maximum body mass (74\% [63-83\%]), and in the difference between minimum and maximum body mass (49\% [3564\%]).

There were significant differences among populations and F1 generations in minimum body mass (LMM: $\mathrm{F}_{3,15}=6.64$, $p=0.005$, Fig. 1, Table S1). Furthermore, males had higher minimum body mass than females (LMM: $\mathrm{F}_{1,21}=7.59$, $p=0.012$ ). Post hoc tests revealed significant differences between the two parent populations (Iceland vs. Norway, $p=0.003$ ), between the F1 pure Norwegian offspring and the Icelandic birds $(p<0.001)$, and between the F1-hybrids and the F1 pure Norwegian offspring $(p=0.015)$. No differences were found between the F1-hybrids and their parental populations (Norway x Iceland vs. Iceland, $p=0.407$; Norway $\mathrm{x}$ Iceland vs. Norway, $p=0.213$ ), nor between the Norwegian parents and the F1 pure Norwegian offspring $(p=0.554)$. This result highlights differences in minimum body mass between populations, most likely as a result of differences in structural size. The way these differences are transmitted to the next generation is unclear. The F1-hybrids had values closer to those of their Icelandic parents, which might indicate possible maternal effects, since only one of the ten hybrids was born from an Icelandic father.

There was a significant difference in maximum voluntary fuelling potential among populations and F1 generations (LMM: $\mathrm{F}_{3,15}=12.11, p<0.001$, Fig. 1 , Table S2), but no 


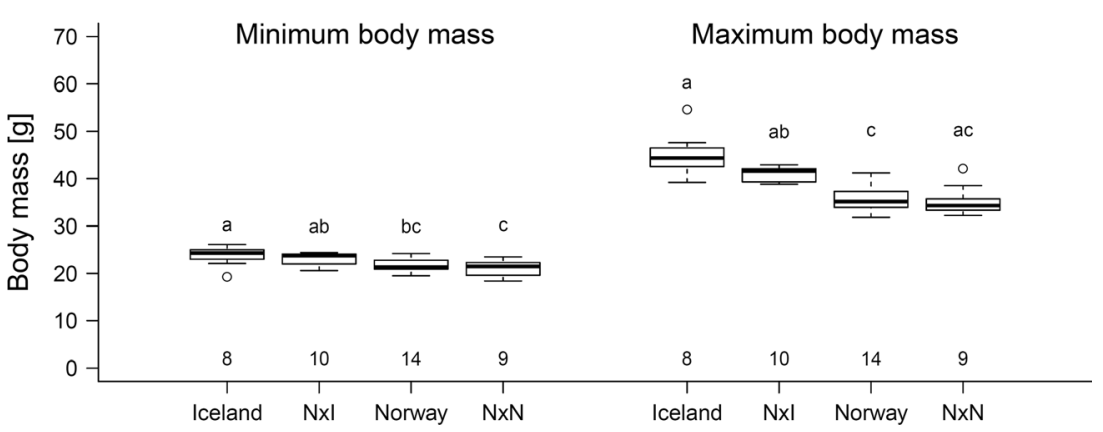

Fig. 1 Minimum and maximum body mass in the four groups studied. Icelandic and Norwegian birds were born in the wild, while Norway $\mathrm{x}$ Iceland and Norway $\mathrm{x}$ Norway birds were from the F1 generation bred in captivity. Sample sizes are given below the boxplots. Letters above the boxplots indicate significant differences among groups. Not that for maximum body mass, the statistical tests refer to differences in maximum voluntary fuelling potential and not to the actual maximum mass values (i.e. they account for initial body mass). Minimum body mass was $23.85 \pm 0.76 \mathrm{~g}$ for Icelandic birds, $23.10 \pm 0.41 \mathrm{~g}$ for Norway $\mathrm{x}$ Iceland offspring, $21.69 \pm 0.36 \mathrm{~g}$ for Norwegian birds, and $21.03 \pm 0.56 \mathrm{~g}$ for pure Norwegian offspring. Maximum voluntary fuelling potential was $21.33 \pm 1.50 \mathrm{~g}$ for Icelandic birds, $18.00 \pm 0.22 \mathrm{~g}$ for Norway x Iceland offspring, $14.28 \pm 0.63 \mathrm{~g}$ for Norwegian birds, and $14.37 \pm 0.92 \mathrm{~g}$ for pure Norwegian offspring difference between sexes (LMM: $\mathrm{F}_{1,20}=0.89, p=0.357$ ). The differences were significant between the two parental populations (Iceland vs. Norway, $p<0.001$ ), between the F1 pure Norwegian offspring and the Icelandic birds $(p<0.001)$, and between the F1-hybrids and the Norwegian population $(p=0.024)$. The difference between the F1 pure Norwegian offspring and the Icelandic birds was marginally nonsignificant $(p=0.075)$, as was the difference between the F1-hybrids and the Icelandic population $(p=0.067)$. There was no significant difference between the Norwegian parents and their pure $\mathrm{F} 1$ offspring $(p>0.5)$. Minimum body mass had no significant effect on maximum voluntary fuelling potential (LMM: $\mathrm{F}_{1,20}=0.14, p=0.715$ ), indicating that maximum voluntary fuelling potential does not depend on structural mass, and is developed as a response to specific population needs. This is in line with previous results (Maggini and Bairlein 2010; Bulte and Bairlein 2013) that showed that the high fuel loads carried by Icelandic birds relate to their need to cross the open sea during their migration. The comparison between expected and observed values of maximum voluntary fuelling potential of F1 offspring showed no significant deviation from the expected intermediate values (one-sample $t$ test, $t=-0.55 ; \mathrm{df}=29.9 ; p=0.59$ ). This confirms the prediction that among population differences in maximum voluntary, fuelling potential are inherited directly. Although we cannot completely exclude that early environmental effects might play a role, this seems unlikely. The birds which were taken from the wild in both Norway and Iceland were taken from their nests at 5-9 days of age. However, the pure Norwegian F1 offspring that were born in the common-garden setup did not differ from their parents born in the wild. This suggests no such effect. A difference in early investment by the parents also seems to be an unlikely explanation for the observed intermediate values. If the parents of hybrids would invest more in their offspring, then the offspring would be expected to be more similar to the most influential parent, in our case probably the Icelandic parent, since they are the ones with higher fuelling. It is unlikely that early parental investment could play a role in the potential to refuel later in life, especially since this can be expressed even several years after birth. However, this possibility could be investigated by performing cross-fostering experiments.

With this study, we show that fuel storing in a long-distance migratory songbird is inherited. F1-hybrids of parental populations with significantly different migratory fuelling capacities exhibited intermediate values of fuelling capacity as compared to their respective parent populations. Being an inherited trait, migratory fuelling potential is exposed to selection and thus worth being further considered in the light of recent global climate change (Walther et al. 2002). The genetic basis of physiological traits has important implications on adaptability and micro-evolutionary processes in migratory birds (Bairlein and Hüppop 2004).

Acknowledgements Open access funding provided by University of Veterinary Medicine Vienna. We thank Heiko Schmaljohann and three anonymous reviewers for the comments on the manuscript, and Andreas Lischke, Ulrike Strauss, Ullrich Meier, and Adolf Völk for bird-keeping.

Funding statement This work was supported by a Deutsche Forschungsgemeinschaft grant to F.B.

Compliance with ethical standards All animals were handled according to international ethical standards. Licences for capture were granted from the Ministry for the Environment (Iceland, licence nr. UMH05030044/13-4-1 HS/- and UMH06040104/13-4-1 of 12 May 2006) and the Directorate for Nature Management (Norway, licence nr. 05/3039 ART-VI-ARES of 28 April 2005 and 2005/3039 ARTVIARES of 3 May 2006). The Institute of Avian Research has a general permission for housing birds from the Landesregierung Niedersachsen (LAVES: 509f-42502-32/12 of 30 July 2004), and no additional permissions are required in Germany for behavioural studies. 
Conflicts of interest The authors declare that they have no conflicts of interest.

Open Access This article is distributed under the terms of the Creative Commons Attribution 4.0 International License (http:// creativecommons.org/licenses/by/4.0/), which permits unrestricted use, distribution, and reproduction in any medium, provided you give appropriate credit to the original author(s) and the source, provide a link to the Creative Commons license, and indicate if changes were made.

\section{References}

Alerstam T (1990) Bird migration. Cambridge University Press, Cambridge

Bairlein F, Gwinner E (1994) Nutritional mechanisms and temporal control of migratory energy accumulation in birds. Annu Rev Nutr 14: $187-215$

Bairlein F, Hüppop O (2004) Migratory fuelling and global climate change. Adv Ecol Res 35:33-47

Bairlein F, Norris DR, Nagel R, Bulte M, Voigt CC, Fox JW, Hussell DJT, Schmaljohann $\mathrm{H}$ (2012) Cross-hemisphere migration of a $25 \mathrm{~g}$ songbird. Biol Lett 8:505-507

Bairlein F, Dierschke V, Delingat J, Eikenaar C, Maggini I, Bulte M, Schmaljohann H (2013) Revealing the control of migratory fueling: an integrated approach combining laboratory and field studies in northern wheatears Oenanthe oenanthe. Curr Zool 59:381-392

Battley PF, Piersma T, Rogers DI, Dekinga A, Spaans B, van Gils JA (2004) Do body condition and plumage during fueling predict northwards departure dates of Great Knots Calidris tenuirostris from north-west Australia? Ibis 146:46-60

Berthold P (1974) Circannuale Periodik bei Grasmücken (Sylvia). III: Periodik der Mauser, der Nachtunruhe und des Körpergewichtes bei mediterranen Arten mit unterschiedlichem Zugverhalten. J Ornithol 115:251-272

Berthold P (1996) Control of bird migration. Chapman \& Hall, London

Berthold P, Querner U (1981) Genetic basis of migratory behavior in European warblers. Science 212:77-78

Berthold P, Querner U (1982) Genetic basis of moult, wing length, and body weight in a migratory bird species, Sylvia atricapilla. Experientia 38:801-802

Berthold P, Gwinner E, Klein H (1972) Periodik des Körpergewichtes, der Mauser und der Nachtunruhe bei Sylvia atricapilla und S. borin unter verschiedenen konstanten Bedingungen. J Ornithol 113:170 190

Bulte M, Bairlein F (2013) Endogenous control of migratory behaviour in Alaskan northern wheatears. J Ornithol 154:567-570
Cadée N, Piersma T, Daan S (1996) Endogenous circannual rhythmicity in a non-passerine migrant, the knot Calidris canutus. Ardea 84:7584

Delingat J, Dierschke V, Schmaljohann H, Mendel B, Bairlein F (2006) Daily stopovers as optimal migration strategy in a long-distance migrating passerine: the Northern Wheatear Oenanthe oenanthe. Ardea 94:593-605

Derégnaucourt S, Guyomarc'h JC, Belhamra M (2005) Comparison of migratory tendency in European quail Coturnix c. coturnix, domestic Japanese quail Coturnix c. japonica and their hybrids. Ibis 147: 25-36

Förschler M, Metzger B, Maggini I, Neumann R, Bairlein F (2008) Seebohm's wheatear Oenanthe oenanthe seebohmi in West Africa. Bull Afr Bird Club 15:242-244

Gill RE Jr, Tibbitts TL, Douglas DC, Handel CM, Mulcahy DM, Gottschalck JC, Warnock N, McCaffery BJ, Battley PF, Piersma T (2009) Extreme endurance flights by landbirds crossing the Pacific Ocean: ecological corridor rather than barrier? Proc R Soc Lond B 276:447-457

Gwinner E (1968) Circannuale Periodik als Grundlage des Jahreszeitlichen Funktionswandels bei Zugvögeln: Untersuchungen am Fitis (Phylloscopus trochilus) und am Waldlaubsänger (Phylloscopus sibilatrix). J Ornithol 109:70-95

Gwinner E (1986) Circannual rhythms. Springer, Berlin

Gwinner E (1990) Bird migration: physiology and Ecophysiology. Springer, Berlin

Gwinner E, Biebach H (1977) Endogene Kontrolle der Mauser und der Zugdisposition bei südfinnischen Neuntötern (Lanius collurio). Vogelwarte 29:56-63

Helbig AJ, Berthold P, Mohr G, Querner U (1994) Inheritance of a novel migratory direction in central European blackcaps. Naturwissenschaften 81:184-186

Helm B, Gwinner E (2006) Migratory restlessness in an equatorial nonmigratory bird. PLoS Biol 4:611-614

Holberton RL, Able KP (1992) Persistence of circannual cycles in a migratory bird held in constant dim light. J Comp Physiol A 171: 477-481

Keith S, Urban EK, Fry CH (1996) Birds of Africa, vol 4. Academic Press, London

Maggini I, Bairlein F (2010) Endogenous rhythms of seasonal migratory body mass change and nocturnal restlessness in different populations of northern wheatear Oenanthe oenanthe. J Biol Rhythm 25: 268-276

Walther G-R, Post E, Convey A, Menzel A, Parmesan C, Beebee TJC, Fromentin J-M, Hoegh-Guldberg O, Bairlein F (2002) Ecological responses to recent climate change. Nature 416:389-395 